\title{
A contrast-based account of word-final tensing
}

\author{
Benjamin Storme and Mélanie Lancien \\ Université de Lausanne
}

\section{Introduction}

Cross-linguistically, vowel systems commonly distinguish between two sets of vowels: tense and lax. Lax vowels are more central than tense vowels in the acoustic space defined by the first and second vowel formants, as schematically represented in Figure 1. Tense and lax vowels may also differ along other dimensions. For instance, tense vowels are often longer (Jakobson et al., 1952:36-39; Lindau, 1978:557559; Stevens, 1998:294-299), although not necessarily so (cf. Southern French; Storme, 2017).

$\mathrm{F} 2(\mathrm{~Hz})$

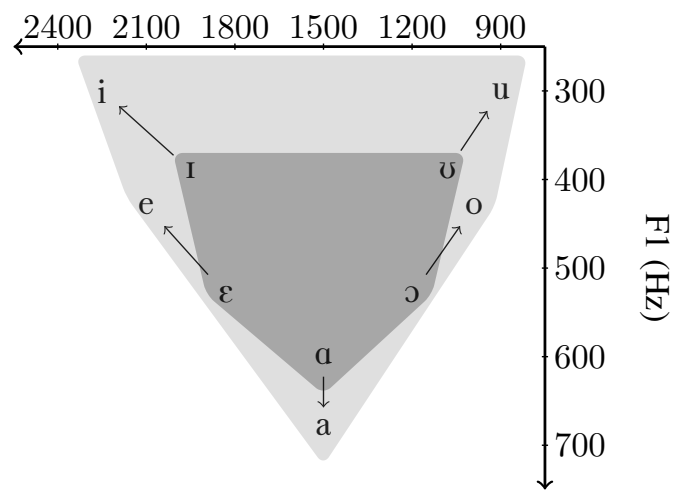

Figure 1: Schematic representation of tense vowels (in the light gray area) and lax vowels (in the dark gray area) in the $\mathrm{F} 1 \times \mathrm{F} 2$ space.

Although tense and lax vowels may be used contrastively, the contrast is often neutralized contextually. This paper focuses on the asymmetry between two contexts: word-final syllables before consonants (_C\#) and word-final positions (_\#). Some languages are reported to allow tense-lax contrasts in both contexts: for instance, in Paluai (Austronesian), $[\mathrm{u}]$ and $[\mho]$ are available both in _ C\# and in _ \# (Schokkin, 2014:38). However, some languages only license tense-lax contrasts in _ C\#. For instance, in Dutch and Standard French, tense and lax vowels contrast in _ C\#, as shown in (1 a), but not in _\#, where only tense vowels are permitted, as shown in (1 b). In the remainder of this paper, this pattern of contextual neutralization will be referred to as word-final tensing. Tensing is represented with arrows going from the lax vowels to their tense counterparts in Figure 1.

(1) (a) Tense-lax contrasts in $\mathrm{C \#}$

$\begin{array}{llll}{[\mathrm{a}]-[\mathrm{a}]} & {[\mathrm{ram}]} & \text { 'window' } & \text { (Dutch; Trommelen, 1983) } \\ & {[\mathrm{ram}]} & \text { 'ram' } & \\ {[\mathrm{o}]-[\mathrm{o}]} & {[\mathrm{bok}]} & \text { 'hoarse' } & \text { (Standard French; Tranel, 1987) } \\ & {[\text { [sok }]} & \text { 'rock' } & \end{array}$

(b) Neutralization of tense-lax contrasts in _\#

\footnotetext{
* We would like to thank Isabelle Racine and Helene Andreassen for giving us access to the data they collected in Switzerland for the project Phonologie du Français Contemporain, and Marie-Hélène Côté for helpful discussion. We also thank the reviewers and participants in GLOW 42 and AMP 2019 for helpful feedback.
} 


\begin{tabular}{|c|c|c|c|}
\hline$[\mathrm{a}]-*[\mathrm{a}]$ & [mika] & 'mica' & (Dutch) \\
\hline$[\mathrm{o}]-*[\mathrm{o}]$ & $\begin{array}{l}*[\mathrm{mika}] \\
{[\mathrm{mo}]} \\
*[\mathrm{mo}]\end{array}$ & 'word' & \\
\hline
\end{tabular}

The paper aims to answer the following question: what motivates word-final tensing? An explanation based on hyperarticulation has been put forth in the literature, for instance by Botma \& van Oostendorp (2012:151):

A vowel in an open syllable has more 'space' and so a more 'pronounced' articulation, which is manifested phonetically by a greater length and tenseness.

In a nutshell, this analysis assumes the following mechanism to account for word-final tensing: (i) vowels are lengthened word-finally (or in open syllables more generally), (ii) lengthening results in vowels being hyperarticulated, and (iii) hyperarticulation results in vowels being more peripheral, i.e. closer to the acoustic targets of tense vowels. However, this proposal is problematic. Word-final tensing is a pattern of contextual neutralization: the contrast between tense and lax vowels (e.g. [o]-[0]) gets neutralized word-finally, where only tense vowels are available (e.g. [o]). Contextual neutralization generally arises when a contrast is not sufficiently distinct perceptually in the relevant context and therefore tends to fail to be perceived by listeners (Ohala, 1981; Steriade, 1997). However hyperarticulation does not reduce but increases contrast distinctiveness: for instance, in French and German, hyperarticulated lax vowels do not get closer to their tense counterparts, but more distant from them (see Gendrot \& Adda-Decker 2005). Therefore, there is no reason for hyperarticulation to result in a neutralization of tense-lax contrasts.

This paper proposes an alternative analysis where tensing is an indirect consequence of the loss of duration contrasts word-finally (see also Storme, 2019:310). Word-final positions are well known contexts for the neutralization of duration contrasts. In languages where tense and lax vowels differ both spectrally and temporally, word-final neutralization of duration contrasts results in tense-lax pairs differing only spectrally. If this spectral difference is not sufficient to support a phonemic contrast, the tense-lax contrast is neutralized altogether. The preference for tense vowels in case of neutralization can be explained as an effect of vowel dispersion: tense vowels are more peripheral in the $\mathrm{F} 1 \times \mathrm{F} 2$ space and therefore more distinct from each other spectrally. This account is compatible with phonetically based accounts of contextual neutralization: wordfinal tensing is ultimately analyzed as a consequence of duration contrasts being perceptually weak wordfinally. It is also compatible with Dispersion Theory (Liljencrants \& Lindblom, 1972; Flemming, 2004): tensing embodies a preference for more distinct vowel contrasts in the $\mathrm{F} 1 \times \mathrm{F} 2$ space.

Section 2 briefly motivates the main hypotheses underlying this account. Section 3 provides evidence for a key hypothesis of the account, namely that the loss of duration contrasts is a phonetic precursor to word-final tensing. The evidence comes from an acoustic study of Swiss French showing that, although tense-lax contrasts are maintained both before word-final consonants and word-finally in this variety, they are signaled by temporal cues only before word-final consonants. Section 4 provides a sketch analysis of word-final tensing in Dispersion Theory (Flemming, 2002, 2004), a theory using distinctiveness constraints to capture the effects of perceptual contrast on phonological patterns. The analysis makes a case for including both spectral and temporal dimensions in Dispersion-Theoretic models of vowel inventories and vowel phonotactics.

\section{Motivating the analysis}

2.1 Neutralization of duration contrasts word-finally The hypothesis that vowel-duration contrasts lack robust temporal cues word-finally is central in the present analysis. This hypothesis is supported by typological evidence that vowel-duration contrasts are often neutralized word-finally specifically (see Myers \& Hansen, 2007 for a survey). For instance, in Kinyarwanda, duration contrasts are available in wordpenultimate syllables but not in word-final syllables, where only short vowels occur (Myers, 2005, Myers \& Hansen, 2007:161). According to Myers \& Hansen (2007:162), this pattern of word-final shortening is due to utterance-final devoicing: vowels are partially devoiced utterance-finally, leading listeners to reinterpret utterance-final vowels as short and therefore to neutralize the contrast between long and short vowels in this position. Neutralization is then extended from strictly utterance-final contexts to word-final contexts by domain generalization (Myers \& Padgett, 2014). Myers \& Hansen also report a few cases where 
neutralization favors long rather than short vowels word-finally (e.g. Tigre). In this case, they propose domain-final lengthening as the phonetic source for phonological neutralization.

2.2 Spectral and temporal cues for the tense-lax contrast In the current account, the loss of duration contrasts is a phonetic precursor to word-final tensing. This results in the following prediction: word-final tensing should only happen in languages where the tense-lax distinction is signaled both by quality and duration. Note that this prediction is not trivial because tenseness and longer duration do not always go together across languages. For instance, some languages have vowel contrasts that could be characterized as tense vs. lax spectrally but are not reported to involve duration as a cue (e.g. Italian [e o] vs. [ $\varepsilon$ o]). Conversely, some languages have vowel contrasts involving duration but without any corresponding spectral differences that could be characterized as tense vs. lax (e.g. Finnish).

The prediction that word-final tensing implies a phonological system with tense and lax vowels differing both spectrally and temporally happens to be borne out: languages notoriously reported to have word-final tensing, i.e. Germanic languages (Stevens, 1998) and Standard French (Tranel, 1987; Gottfried \& Beddor, 1988), happen to have tense-lax pairs differing along the two dimensions, with tense vowels being both more peripheral and longer than their lax counterparts.

Interestingly, in Standard French, the phonological distribution of tense-lax contrasts correlates with the acoustic correlates of these contrasts in a way that is compatible with the present account. Indeed, [o]-[0] differ both spectrally and temporally ([o] is more peripheral and longer than [0]; Tranel, 1987; Gottfried \& Beddor, 1988) and are subject to word-final tensing, as illustrated in (1 a) and (1 b). However, [e]-[e] only differ spectrally: to our knowledge, no study reports a temporal difference between the two vowels

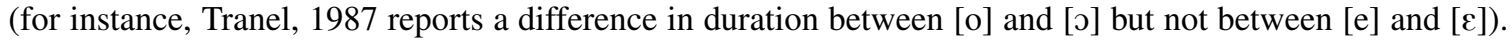
And crucially [e]-[ع] are not subject to word-final tensing, as illustrated in (2). This correlation between phonological behavior and phonetic implementation is in line with the current account: no neutralization is expected if duration does not play a role in the corresponding tense-lax contrast.

(2) $[\mathrm{e}]-[\varepsilon]$ contrast in \# \# in Standard French

$\begin{array}{lll}\text { thé } & {[\mathrm{te}]} & \text { 'tea' } \\ \text { taie } & {[\mathrm{t} \varepsilon]} & \text { 'pillow case' }\end{array}$

2.3 Tensing as enhancement of vowel contrasts A complete account of word-final tensing must also explain why the loss of the contrast results in tensing rather than laxing. Following Storme (2019), we propose that tense vowels are preferred to lax vowels because they are more peripheral in the $\mathrm{F} 1 \times \mathrm{F} 2$ space (e.g. French: Jakobson et al., 1952:36-39; English: Stevens, 1998:296; Javanese: van Zanten, 1989:72; Quebec French: Martin, 2002; etc.), therefore allowing for better vowel discrimination by listeners. This proposal is in line with dispersion-theoretic accounts of the structure of vowel inventories, where dispersion in the F1 $\times \mathrm{F} 2$ space plays a key role in accounts of the typology of vowel inventories, e.g. to explain why virtually all vowel inventories include [i a u] (Liljencrants \& Lindblom, 1972; Schwartz et al., 1997a; BeckerKristal, 2010).

\section{Acoustic study of Swiss French}

3.1 Introduction If the loss of duration contrast is a phonetic precursor to word-final tensing, we expect to find languages where the same tense-lax contrast is present both in _ $\mathrm{C \#}$ and in _ \#, but it is signaled by vowel quality and duration in _ C\#, but only by vowel quality in _\#. Swiss French varieties offer an opportunity to test this prediction as, contrary to Standard French, some of them allow the same tenselax contrast [o]-[0] in both contexts (see Racine \& Andreassen, 2012 on Swiss French variety spoken in Neuchâtel), as illustrated in (3).

(3) [o]-[0] contrasts in Swiss French

\begin{tabular}{|c|c|c|}
\hline C\# & [o]-[э] & [воk] \\
\hline & & [вәk] \\
\hline \# & [o]-[ग] & $\begin{array}{l}{[\mathrm{mo}]} \\
{[\mathrm{mo}]}\end{array}$ \\
\hline
\end{tabular}


To our knowledge, no study has directly compared the acoustic distinctiveness of [o]-[0] across the two contexts in Swiss French. In a small acoustic study focusing on the _C\# context, Miller \& Grosjean (1997) found that [o]-[0] differ both spectrally and temporally, as in Standard French. However, for the \# context, Racine \& Andreassen (2012) only found a spectral difference between the two vowels. Taken together, the results of these two studies support the hypothesis of a greater distinctiveness of [o]-[0] in _ C\# (where both spectral and temporal cues are available) than in _\# (where only spectral cues are available). However, this hypothesis needs to be further confirmed by a direct comparison of the contrast in the two contexts for the same group of speakers. This was the goal of the study reported in this section.

3.2 Methods In this study we used spoken data by Swiss native speakers belonging to the project Phonologie du Français Contemporain (PFC; Andreassen, 2003; Andreassen et al., 2010; Racine \& Andreassen, 2012). Although the project includes both read and spontaneous speech, we only focused on read words to study the tense-lax contrast. There were two reasons for this choice. First, as PFC word lists were compiled specifically to study this type of vowel contrasts, they include the relevant word types to test our hypothesis (e.g. minimal pairs such as maux [mo] 'evils' - mot [mo] 'word'). Second, words occur utterance-finally in these lists and this is precisely the context where neutralization of duration contrasts is phonetically motivated. In addition with [o]-[o], we also included [e]-[ع] in our dataset in order to test whether this contrast is only signaled by spectral cues, as suggested by previous research. Note that this contrast is limited to word-final positions in Standard and Swiss French (before word-final consonants, only the lax vowel occurs). Therefore, contrary to [o]-[0], it is not possible to compare the phonetic realization of the contrast in the two contexts.

We used data from 24 speakers, males and females, born either in Neuchâtel or Nyon (see the map in Figure 2). The 12 speakers from Neuchâtel read three word lists, and the 12 speakers from Nyon read two word lists, for a total of 71 word types and 1'297 utterances of those words exhibiting the target contrasts. Words and phones were automatically segmented under Praat (Boersma \& Weenink, 2018) using EasyAlign (Goldman, 2011). We performed a manual correction for the phone segmentation (based on F2 and F3 beginning and end). Then we used a Praat script to automatically extract values for target vowels' duration, mean F1 and mean F2, as well as their phone label, and word label. Mean F1 and F2 were extracted in $\mathrm{Hz}$ and vowel duration in seconds. As there is a lot of variation across speakers for the realization of the wordfinal [o]-[0] contrast in Swiss French (Schouwey, 2008), one of the authors listened to the word-final [o]-[0] stimuli individually and re-assigned them labels ([o] or [o]) on a perceptive basis.

All words, contexts, and speakers pooled, a total of 1'297 tokens of vowels were acoustically analyzed. A summary of this corpus is showed in Table 1.

\begin{tabular}{clllll}
\hline \hline Context & \multicolumn{4}{c}{ Vowel } & \multicolumn{1}{c}{ Total } \\
\hline & $\mathrm{e}$ & $\varepsilon$ & $\mathrm{o}$ & $\mathrm{O}$ & \\
\hline$-\#$ & 606 & 267 & 148 & 55 & 1076 \\
& $56.3 \%$ & $24.8 \%$ & $13.8 \%$ & $5.1 \%$ & $100 \%$ \\
\hline$-\mathrm{C} \#$ & - & - & 84 & 137 & 221 \\
& & & $38 \%$ & $62 \%$ & $100 \%$ \\
\hline Total & 606 & 267 & 232 & 192 & 1297 \\
& $46.7 \%$ & $20.6 \%$ & $17.9 \%$ & $14.8 \%$ & $100 \%$ \\
\hline \hline
\end{tabular}

Table 1: Total number of tokens for each vowel category in _\# and _ C\# (all words and speakers pooled).

The data were analyzed using a mixed effects model (Bates et al., 2015) in R (R Core Team, 2019). Tenseness (tense vs. lax), context $\left(\mathrm{V}_{\text {front }} \#, \mathrm{~V}_{\text {back }} \#\right.$, or $\left.\mathrm{V}_{\text {back }} \mathrm{C} \#\right)$, and speakers' regional origin (Nyon vs. Neuchâtel) were set as fixed effects. We also analyzed the interactions between these three factors. Random intercepts were set for speaker, word, preceding segment, and following segment. P-values were obtained using the lmerTest package (Kuznetsova et al., 2015).

3.3 Results The results for F1, F2, and duration are shown in Figures 3, 4, and 5, respectively. In these

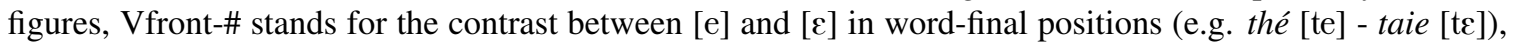
Vback-\# for the contrast between [o] and [o] in word-final positions (e.g. maux [mo] - mot [mo]), and Vback- 


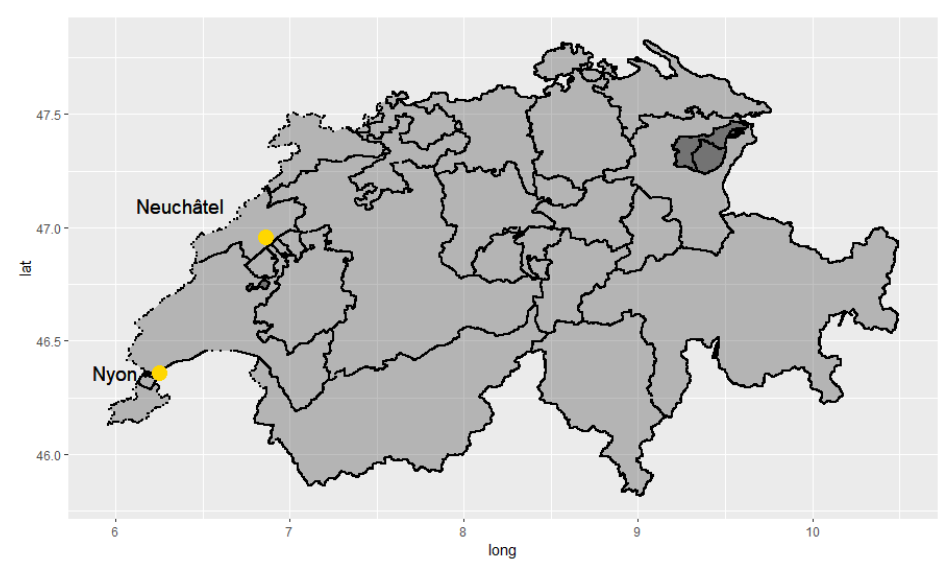

Figure 2: Map of Switzerland

C\# for the contrast between [o] and [o] before word-final consonants (e.g. côte [kot] - cote [kot]).

3.3.1 F1 As expected, lax vowels were found to have significantly higher $\mathrm{F} 1$ values than the corresponding tense vowels $(81.1 \pm 4.7 \mathrm{~Hz} ; \mathrm{t}=17.4, \mathrm{p}<.001)$, although the difference was found to be smaller in Neuchâtel than in Nyon $(-20.7 \pm 4.0 \mathrm{~Hz}, \mathrm{t}=-5.2, \mathrm{p}<.001)$. Post-hoc tests showed that a significant F1 difference was maintained between tense and lax vowels in the three contexts in each of the two varieties.

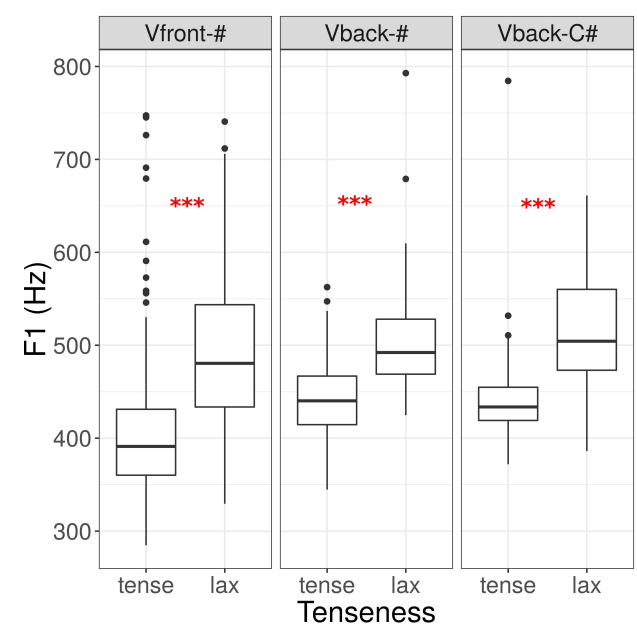

Figure 3: F1

3.3.2 $\quad F 2 \quad$ As expected, lax vowels were found to be on average more central along $F 2$ than their tense counterparts: $[\varepsilon]$ was found to correspond to a smaller $\mathrm{F} 2$ value than $[\mathrm{e}](-174.9 \pm 22.7 \mathrm{~Hz}, \mathrm{t}=-7.7, \mathrm{p}<.001)$ and [o] to a larger F2 value than [o], both word-finally $(97.8 \pm 45.2 \mathrm{~Hz}, \mathrm{t}=2.2, \mathrm{p}<.05)$ and before word-final consonants $(324.0 \pm 44 \mathrm{~Hz}, \mathrm{t}=7.5, \mathrm{p}<.001)$. However post-hoc tests showed that word-final [o] and [o] had significantly different $\mathrm{F} 2$ values in the Nyon variety $(221.7 \pm 79.5 \mathrm{~Hz}, \mathrm{t}=2.8, \mathrm{p}<.05)$ but not in the Neuchâtel variety $(-26.0 \pm 40.3 \mathrm{~Hz}, \mathrm{t}=-0.6, \mathrm{p}=.52)$. 


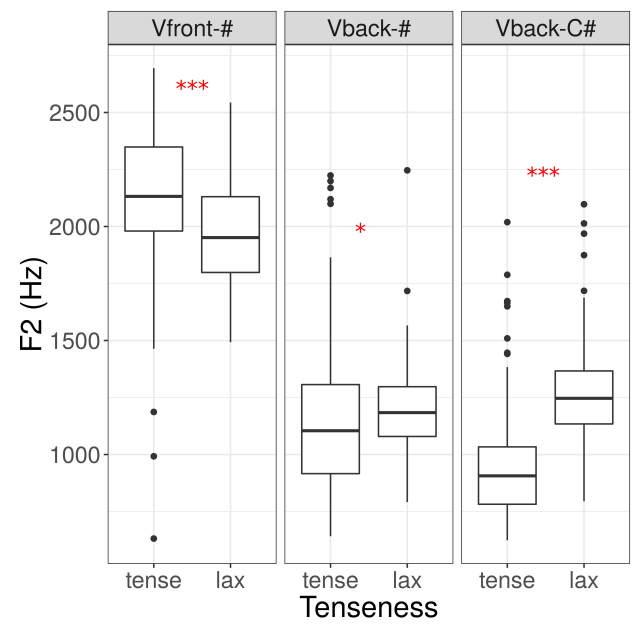

Figure 4: F2

3.3.3 Duration As expected, [0] was found to be shorter than [o] before word-final consonants (-105 \pm 37 $\mathrm{ms}, \mathrm{t}=-2.9, \mathrm{p}<.05)$ but no significant difference was found between tense and lax vowels word-finally, neither for [o]-[0] $(1 \pm 11 \mathrm{~ms}, \mathrm{t}=.07, \mathrm{p}=.95)$ nor for $[\mathrm{e}]-[\varepsilon](-22 \pm 14 \mathrm{~ms}, \mathrm{t}=-1.57, \mathrm{p}=.12)$. Post-hoc tests showed that this pattern held in both Neuchâtel and Nyon varieties.

The lax vowel appears to be lengthened word-finally: [0] is longer word-finally than before word-final consonants. This is consistent with the patterns described by Myers \& Hansen (2007) as involving domainfinal lengthening (see subsection 2.1).

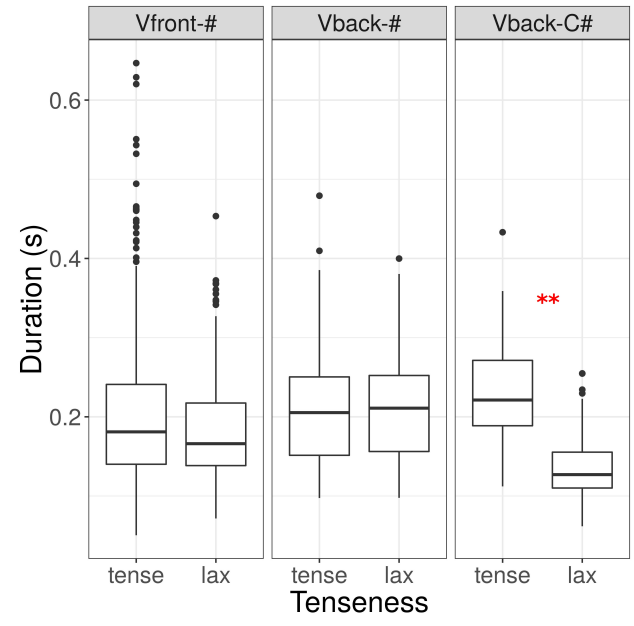

Figure 5: Duration

3.4 Discussion Tense and lax vowels were found to differ spectrally in all three contexts considered in the study $([\mathrm{e}]-[\varepsilon]$ in _\#, [o]-[o] in \# and _ C\#) but temporal differences were only found before word-final consonants (for [o]-[0] in _ C\#). These findings support the hypothesis that tense-lax contrasts are temporally weaker word-finally than before word-final consonants.

We also found a result that we did not expect but is still compatible with the overall account. The two Swiss varieties were found to partially differ in their specific implementations of the tense-lax contrast along F1 and F2: (i) F1 differences between tense and lax vowels were larger in the Neuchâtel variety than in the 
Nyon variety and (ii) F2 did not play a role in the [o]-[0] contrast word-finally in the Neuchâtel variety. This suggests that the tense-lax contrast in French essentially involves F1, with the use of F2 being more variable. The fact that only F1 is consistently involved in the tense-lax pair [ø]-[œ] in the French variety studied by (Storme, 2017) points to the same conclusion (This pair was not included in the present study due to its very low functional load).

\section{Dispersion-Theoretic analysis}

4.1 Deriving word-final tensing and word-final contrast maintenance To model word-final tensing, we use Dispersion Theory as implemented in Optimality Theory by Flemming $(2002,2004)$. In particular, we use the serial model of Flemming (2008) (see also Stanton, 2017) where: (i) phonemes are selected in the inventory module and (ii) phoneme sequences are selected in a subsequent, phonotactic module. The serial model allows us to focus on the problem that interests us most here: the pattern of contextual neutralization. Assume that the inventory module has delivered a pair of tense and lax vowels differing both spectrally and temporally (i.e. [o:]-[0]) and a single consonant (noted C). The phonotactic module selects the inventory of rimes (i.e. $\mathrm{V \#}$ and $\mathrm{VC \#}$ sequences) that realizes the best compromise among a set of phonological constraints, including distinctiveness constraints. Distinctiveness constraint penalize contrasts according to their distinctiveness: less distinct contrasts are more penalized than more distinct contrasts and the absence of contrast (i.e. neutralization) is not penalized. Here, we use a single distinctiveness constraint (called DIST) that penalizes contrasts according to their distinctiveness, as further explained in (4a). In addition, we assume the constraints in (4b) through $(4 \mathrm{~d}) . * \mathrm{~V} \#$ is the constraint that drives word-final lengthening in Swiss French. ${ }^{1}$ *LAX is the constraint responsible for tensing. In a more complete analysis including other vowel qualities beyond [o]-[0], this constraint could be restated as a distinctiveness constraint, on the assumption that contrasts among tense vowels (e.g. [e]-[o]) are more distinct than contrasts among lax vowels

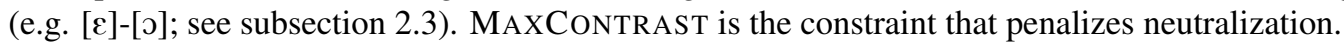

(4) (a) DIST

This constraint assigns a greater penalty to tense-lax contrasts that are less distinct: (i) it assigns one penalty (*) to tense-lax contrasts that differ both spectrally and temporally, (ii) it assigns two penalties to tense-lax contrasts that differ only spectrally, (iii) it does not penalize the absence of tense-lax contrast.

(b) $* \mathrm{~V} \#$

This constraint penalizes short word-final vowels.

(c) * LAX

This constraint penalizes vowels that are lax spectrally (i.e. [०] and [ə:]).

(d) MAXCONTRAST

This constraint favors larger inventories of rimes: it assigns a bonus $(\mathcal{})$ for each rime in the inventory.

Word-final tensing in a language like Standard French can be derived with the ranking illustrated in Table 2. Candidate (a) includes all four rimes but violates the top ranked constraint penalizing short vowels wordfinally $(* \mathrm{~V} \#)$. Candidate (b) solves the phonotactic problem of word-final short vowels by lengthening the lax vowel in this context. However it does so at the cost of making vowel contrasts less distinct: lengthening of the lax vowel results in the loss of the temporal cue distinguishing tense and lax vowels. This loss of distinctiveness is penalized by the distinctiveness constraint DIST. The pairs of rimes responsible for specific violations of DIST are shown in subscripts. The candidate featuring word-final tensing (candidate (c)) solves the problem of insufficient distinctiveness by neutralizing the tense-lax contrast all together word-finally. MAXCONTRAST is sufficiently low ranked to allow for neutralization. Candidate (d) also solves the problem of insufficient distinctiveness with neutralization but it is worse than candidate (c) because it features a lax vowel word-finally and lax vowels are penalized by *Lax.

\footnotetext{
1 This constraint is used because lax vowels are lengthened word-finally in Swiss French. In a language where neutralization favors short vowels rather than long vowels, a constraint penalizing word-final long vowels (*V:\#) should be used instead. See subsection 2.1 on the phonetic motivation for these constraints.
} 


\begin{tabular}{|c|c|c|c|c|c|c|c|c|c|}
\hline & & & & & & $* \mathrm{~V} \#$ & DIST & *LAX & MAXCONTRAST \\
\hline \multirow{4}{*}{ 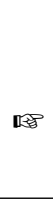 } & (a) & O: & 0 & o:C & oC & \multirow[t]{4}{*}{$*$} & $*_{0:-0} *_{0: C-\supset C}$ & ** & $\checkmark \checkmark \checkmark \checkmark$ \\
\hline & (b) & o: & o: & $\mathrm{o}: \mathrm{C}$ & əC & & $*_{0:-\mathrm{O}}{ }^{*}{ }_{\mathrm{o}: \mathrm{C}-\mathrm{O}}$ & ** & $\checkmark \checkmark \checkmark \checkmark$ \\
\hline & (c) & O: & & o:C & əC & & $*_{\mathrm{O}: \mathrm{C}-\mathrm{O} C}$ & $*$ & $\checkmark \checkmark \checkmark$ \\
\hline & (d) & & o: & $\mathrm{o:C}$ & əC & & $*_{0: C-\rho C}$ & $* *$ & $\checkmark \checkmark \checkmark$ \\
\hline
\end{tabular}

Table 2: Analysis of Standard French

\begin{tabular}{|c|c|c|c|c|c|c|c|c|c|}
\hline & & & & & & $* \mathrm{~V} \#$ & MAXCONTRAST & DIST & *LAX \\
\hline \multirow{4}{*}{$\theta \notin$} & (a) & O: & o & o:C & oC & $*$ & $\checkmark \checkmark \checkmark \checkmark$ & $*_{\mathrm{O}:-\mathrm{O}} *_{\mathrm{O}: \mathrm{C}-\mathrm{DC}}$ & $* *$ \\
\hline & (b) & O: & ว: & $\mathrm{o:C}$ & ¡C & & $\checkmark \checkmark \checkmark \checkmark$ & $* *_{0:-\mathrm{O}:}{ }{ }_{\mathrm{o}: \mathrm{C}-\mathrm{DC}}$ & $* *$ \\
\hline & (c) & o: & & o:C & ¡C & & $\checkmark \checkmark \checkmark$ & $*_{0: C-\partial C}$ & * \\
\hline & (d) & & ว: & $\mathrm{o}: \mathrm{C}$ & „C & & $\checkmark \checkmark \checkmark$ & $*_{\mathrm{O}: \mathrm{C}-\mathrm{DC}}$ & $* *$ \\
\hline
\end{tabular}

Table 3: Analysis of Swiss French

The analysis can also derive the pattern attested in Swiss French, with tense and lax vowels differing only spectrally word-finally. This pattern is derived when $* \mathrm{~V} \#$ and MAXCONTRAST are top ranked, as illustrated in Table 3. As before, candidate (a) includes all four rimes but violates the top ranked constraint penalizing short vowels word-finally $(* \mathrm{~V} \#)$. However, now, MAXCONTRAST is higher ranked than the constraint that penalizes the perceptually problematic [o:]-[o:] contrast. As a consequence, the candidate that maintains the contrast word-finally (candidate (b)) is preferred to the candidate featuring word-final tensing (candidate (c)).

4.2 Deriving word-final high-vowel laxing In the analysis, the candidate with word-final laxing (candidate (d)) is harmonically bounded by the candidate with word-final tensing (candidate (c)). ${ }^{2}$ The analysis presented here therefore predicts that no language should neutralize a tense-lax contrast word-finally and favor lax vowels in this context. However, some languages do feature word-final laxing, in particular high-vowel laxing. ${ }^{3}$ Word-final high-vowel laxing may be found in languages where tense and lax vowels are in allophonic distribution. For instance, in Turkish, the front high vowel has a tense allophone [i] in _C\# and a lax allophone [I] in \#\# (Göksel \& Kerslake, 2005:11). Similarly, in Tudanca Spanish, high vowels /i u/ have lax (or centralized) allophones in unstressed word-final positions (Hualde, 1989:779). Word-final high-vowel laxing may also be involved in patterns of contextual neutralization. In Latin, short [i] and [e] are available before final consonants (e.g. quid 'what' vs. sed 'but') but /i/ is centralized and realized as [e] word-finally (see mari > mare 'sea'; Oniga, 2014:56). As a consequence, the contrast between short [i] and short [e] is neutralized word-finally. The change from /i/ to [e] can be analyzed as laxing (at least spectrally) as it involves centralizing along both F1 and F2.

How to account for word-final high-vowel laxing in these languages (whether it is involved in patterns of allophonic distribution or contextual neutralization)? We propose that this process is motivated by vowel reduction. As noted in subsection 2.1, some languages have shorter vowels word-finally, due to utterancefinal devoicing according to Myers \& Hansen (2007). Shortening of high vowels may result in centralization along both F1 and F2, i.e. in laxing (see Gendrot \& Adda-Decker, 2005 for evidence in French and German). The fact that word-final high-vowel laxing is limited to unstressed syllables in Tudanca Spanish (Hualde, 1989:779) is compatible with the vowel-reduction analysis: vowel reduction may target unstressed syllables specifically (Crosswhite, 2004). The fact that word-final laxing seems to specifically target high vowels but

\footnotetext{
2 This is the case regardless of the word-final vowel's duration: candidate $/ 0 \mathrm{o:C} \mathrm{\jmath C} /$ (with a word-final short lax vowel) would also be harmonically bounded by candidate /o o:C $\mathrm{\jmath C}$ (with a word-final short tense vowel).

3 Thanks to Michael Becker for bringing this fact to our attention.
} 
not mid vowels is also compatible with the vowel-reduction analysis: high vowels may get lower when they get shorter but mid vowels do not (see Gendrot \& Adda-Decker, 2005 for evidence in French and German). Note that the analysis predicts that laxing should only be observed if word-final high vowels are subject to shortening. In other words, candidate / I iC IC/ (with a short high vowel word-finally) will be derived by the analysis, but not candidate /r: $\mathrm{iC} \mathrm{IC} /$ (with a long high vowel word-finally). In order to derive high-vowel laxing formally, effort constraints responsible for vowel reduction should be added to the model sketched in this section (see Flemming, 2004, 2005 for a proposal).

\section{Conclusion}

This work is in line with Dispersion-Theoretic accounts of vowel inventories and vowel phonotactics, where contrast distinctiveness plays an important role in explaining crosslinguistic trends (see Liljencrants \& Lindblom, 1972; Flemming, 2002). In particular, the contextual distinctiveness of duration contrasts was key in deriving the asymmetry between _\# and _ C\#. The present work also points to the need to include vowel duration alongside F1 and F2 in Dispersion-Theoretic models of vowel patterns. Although vowel quality and vowel duration are known to interact in perception (cf. Miller \& Grosjean, 1997; Winn et al., 2012), typological Dispersion-Theoretic models generally focus on vowel quality alone (cf. Liljencrants \& Lindblom, 1972; Schwartz et al., 1997b). The present work suggests that this view is too simplistic: distinctiveness along both spectral and temporal dimensions is relevant to understand the typology of phonological patterns.

\section{References}

Andreassen, Helene N. (2003). Comment le schwa et la consonne de liaison vacillent et s'évanouissent dans le vaudois : un traitement de la variation. Master's thesis, University of Troms $\emptyset$.

Andreassen, Helene N., R. Maître \& Isabelle Racine (2010). La Suisse. Detey, Sylvain, Jacques Durand, Bernard Laks \& Chantal Lyche (eds.), Les variétés du français parlé dans l'espace francophone, Ophrys, Paris, 211-233.

Bates, Douglas, Martin Mächler, Ben Bolker \& Steve Walker (2015). Fitting linear mixed-effects models using lme4. Journal of Statistical Software 67:1, 1-48.

Becker-Kristal, Roy (2010). Acoustic typology of vowel inventories and Dispersion Theory: Insights from a large crosslinguistic corpus. Ph.D. thesis, UCLA.

Boersma, Paul \& David Weenink (2018). Praat: doing phonetics by computer [computer program]. version 6.0.37. URL http://www.praat.org/. Retrieved March 14, 2018.

Botma, Bert \& Marc van Oostendorp (2012). A propos of the Dutch vowel system 21 years on, 22 years on. Botma, Bert \& Roland Noske (eds.), Phonological Explorations. Empirical, Theoretical and Diachronic Issues, De Gruyter, Berlin/Boston, 135-154.

Crosswhite, Katherine M. (2004). Vowel reduction. Hayes, Bruce, Robert Kirchner \& Donca Steriade (eds.), Phonetically Based Phonology, Cambridge University Press, Cambridge, 191-231.

Flemming, Edward (2002). Auditory Representations in Phonology. Routledge, London/New York.

Flemming, Edward (2004). Contrast and perceptual distinctiveness. Hayes, Bruce, Robert Kirchner \& Donca Steriade (eds.), Phonetically Based Phonology, Cambridge University Press, Cambridge, 232-276.

Flemming, Edward (2005). A phonetically-based model of vowel reduction. Manuscript.

Flemming, Edward (2008). The realized input. Manuscript.

Gendrot, Cédric \& Martine Adda-Decker (2005). Impact of duration on F1/F2 formant values of oral vowels: an automatic analysis of large broadcast news corpora in French and German. Proceedings of Interspeech'2005 - Eurospeech: 9th European Conference on Speech Communication and Technology, Lisbon, 2453-2456.

Göksel, Asli \& Celia Kerslake (2005). Turkish: a comprehensive grammar. Routledge, London/New York.

Goldman, Jean-Philippe (2011). Easyalign: an automatic phonetic alignment tool under praat .

Gottfried, Terry \& Patrice Speeter Beddor (1988). Perception of temporal and spectral information in French vowels. Language and Speech 31, 57-75.

Hualde, José Ignacio (1989). Autosegmental and metrical spreading in the vowel harmony systems of northwestern spain. Linguistics 27, 773-805.

Jakobson, Roman, C. Gunnar M. Fant \& Morris Halle (1952). Preliminaries to speech analysis: The distinctive features and their correlates. The MIT Press, Cambridge, MA.

Kuznetsova, Alexandra, Per Bruun Brockhoff \& Rune Haubo Bojesen Christensen (2015). lmerTest: Tests in linear mixed effects models. URL http: / / CRAN.R-project.org/package=lmerTest. R package version 2.0-25.

Liljencrants, Johan \& Björn Lindblom (1972). Numerical simulation of vowel quality systems: the role of perceptual contrast. Language 48, 839-862.

Lindau, Mona (1978). Vowel features. Language 54, 541-563. 
Martin, Pierre (2002). Le système vocalique du français du Québec. De l'acoustique à la phonologie. La Linguistique 38, 71-88.

Miller, Joanne L \& Francois Grosjean (1997). Dialect effects in vowel perception: The role of temporal information in French. Language and Speech 40:3, 277-288.

Myers, Scott (2005). Vowel duration and neutralization of vowel length contrasts in Kinyarwanda. Journal of Phonetics $33,427-446$.

Myers, Scott \& Benjamin B. Hansen (2007). The origin of vowel length neutralization in final position: Evidence from Finnish speakers. Natural Language \& Linguistic Theory 25:1, 157-193.

Myers, Scott \& Jaye Padgett (2014). Domain generalisation in artificial language learning. Phonology 31:3, 399-433.

Ohala, John J. (1981). The listener as a source of sound change. Masek, C. S., R. A. Hendrick \& M. F. Miller (eds.), Papers from the Parasession on Language and Behavior, Chicago Linguistic Society, Chicago, 178-203.

Oniga, Renato (2014). Latin: a linguistic introduction. Oxford University Press, Oxford.

R Core Team (2019). R: A Language and Environment for Statistical Computing. R Foundation for Statistical Computing, Vienna, Austria, URL https : / /www.R-project.org/.

Racine, Isabelle \& Helene Andreassen (2012). A phonological study of a Swiss French variety : data from the Canton of Neuchâtel, John Benjamins Publishing Company, Amsterdam/Philadelphia, 211-233.

Schokkin, Gerda Hendrike (2014). A grammar of Paluai: the language of Balluan Island, Papua New Guinea. Ph.D. thesis, James Cook University.

Schouwey, Vanessa (2008). Les variantes cantonales dans la prononciation des voyelles du français en Suisse romande. Master's thesis, University of Geneva.

Schwartz, Jean-Luc, Jean-Louis Boë, Nathalie Vallée \& Christian Abry (1997a). Major trends in vowel system inventories. Journal of Phonetics 25, 233-253.

Schwartz, Jean-Luc, Jean-Louis Boë, Nathalie Vallée \& Christian Abry (1997b). The Dispersion-Focalization Theory of vowel systems. Journal of Phonetics 25, 255-286.

Stanton, Juliet (2017). Constraints on the Distribution of Nasal-Stop Sequences: An Argument for Contrast. Ph.D. thesis, MIT.

Steriade, Donca (1997). Phonetics in phonology: the case of laryngeal neutralization. Manuscript.

Stevens, Kenneth N. (1998). Acoustic Phonetics. The MIT Press, Cambridge, MA/London.

Storme, Benjamin (2017). The loi de position and the acoustics of French mid vowels. Glossa: a journal of general linguistics 2, URL http: / / doi.org/10.5334/gjgl.300.

Storme, Benjamin (2019). Contrast enhancement as motivation for closed syllable laxing and open syllable tensing. Phonology 36, 303-340.

Tranel, Bernard (1987). The sounds of French: An introduction. Cambridge University Press, Cambridge.

Trommelen, Mieke (1983). The Syllable in Dutch. Foris Publications, Dordrecht.

van Zanten, Ellen (1989). The Indonesian vowels: Acoustics and perceptual explorations. Delft, Eburon.

Winn, Matthew B, Monita Chatterjee \& William J Idsardi (2012). The use of acoustic cues for phonetic identification: Effects of spectral degradation and electric hearing. The Journal of the Acoustical Society of America 131:2, 14651479 . 